\title{
Estoque de Serapilheira em Três Fisionomias no Cerrado do Distrito Federal
}

\author{
Nickolas Mendes Matos ${ }^{1}$, Fabiana Piontekowski Ribeiro², Alcides Gatto ${ }^{1}$, \\ Angela Pereira Bussinguer ${ }^{2}$ \\ ${ }^{1}$ Universidade de Brasília - UnB, Brasília/DF, Brasil \\ ${ }^{2}$ Pós-graduação em Ciências Florestais, Universidade de Brasília - UnB, Brasília/DF, Brasil
}

\begin{abstract}
RESUMO
O estudo teve como objetivo avaliar o estoque mensal e anual de serapilheira e sazonalidade em duas fitofisionomias (Cerrado stricto sensu e Mata de Galeria) e em um povoamento de eucalipto, localizados na Fazenda Água Limpa, DF. O estoque de serapilheira foi coletado mensalmente, pelo período de um ano, com auxílio de um gabarito metálico de $0,25 \mathrm{~m}^{2}$. O material foi separado manualmente nas frações folhas, cascas, galhos, raízes, flores/frutos e material particulado. O estoque de serapilheira na Mata de Galeria $\left(9,36 \mathrm{tha}^{-1}\right)$ foi estatisticamente igual ao observado no povoamento de eucalipto $\left(9,12 \mathrm{t} \mathrm{ha}^{-1}\right)$, valores maiores que o verificado no Cerrado Típico $\left(6,08 \mathrm{tha}^{-1}\right)$. A fração folha apresentou maior quantidade nas fitofisionomias e no povoamento quando comparada às demais frações. Verificaram-se dois padrões divergentes de sazonalidade do estoque de serapilheira: maior estoque no Cerrado Típico e no povoamento de eucalipto na estação seca e maior estoque na Mata de Galeria na estação chuvosa.
\end{abstract}

Palavras-chave: ecologia florestal, senescência foliar, sistemas florestais.

\section{Litter Stock in Three Forest Types in Cerrado at Distrito Federal}

\begin{abstract}
The aim of this study was to evaluate the monthly and annual litter stock, and the seasonality in two phytophysiognomies (Cerrado stricto sensu and Gallery Forest) and one eucalyptus plantation, located in Fazenda Água Limpa, DF. The litter stock was monthly collected by using a metal jig of $0.25 \mathrm{~m}^{2}$, during one year. The material was manually sorted into leaves, bark, twigs, roots, flowers/fruits and particulate matter. There were no significant differences in the litter stock between the Gallery Forest $\left(9.36 \mathrm{t} \mathrm{ha}^{-1}\right)$ and the eucalyptus plantation $\left(9.12 \mathrm{tha}^{-1}\right)$, which were both higher than the Cerrado stricto sensu $\left(6.08 \mathrm{t} \mathrm{ha}^{-1}\right)$. The leaf fraction presented a larger amount in the three vegetation types when compared to the other fractions. There were two different patterns of litter stock seasonality: higher litter stock in the Cerrado stricto sensu and eucalyptus plantation in the dry season; and higher stock in Gallery Forest in the rainy season.
\end{abstract}

Keywords: forest ecology, leaf senescence, forest systems. 


\section{INTRODUÇÃO}

A vegetação do Cerrado apresenta as fitofisionomias florestal, savânica e campestre. Dentre estas, predomina no Cerrado stricto sensu a vegetação arbóreo-arbustiva, que cobre aproximadamente de $20 \%$ a $50 \%$ do bioma. Devido à complexidade dos fatores condicionantes (clima, fertilidade do solo, quantidade de chuvas, dentre outros fatores), originam-se subdivisões fisionômicas do Cerrado sentido restrito, sendo as principais Cerrado Denso, Cerrado Típico, Cerrado Ralo e Cerrado Rupestre (Ribeiro \& Walter, 2008).

A Mata de Galeria é uma fitofisionomia florestal, vegetação florestal que acompanha corpos d'água de pequeno porte. Esse tipo de vegetação apresenta uma importante função ecológica e hidrológica, uma vez que protege as margens dos rios, evita assoreamentos e garante, assim, a qualidade e a quantidade de água de seu leito (Ribeiro \& Walter, 2008; Sano et al., 2008).

No entanto, aproximadamente 80 milhões de hectares de Cerrado vêm sendo cultivados com diferentes usos da terra, o que corresponde a 39,5\% da área total do bioma. Entre esses usos, as classes mais representativas são as pastagens cultivadas e atividades agropecuárias que envolvem cultivo de cereais e produção de carne e ocupam, respectivamente, $26,5 \%$ e 10,5\% do Cerrado, tendo tornado o Brasil um dos maiores exportadores de alimentos (Sano et al., 2008; CONAB, 2013).

A substituição das fitofisionomias originais de Cerrado para atender a diferentes atividades antrópicas é extremamente prejudicial aos solos, já que esse fato concorre para a diminuição do aporte de serapilheira. Como consequência, são gerados impactos negativos no conteúdo de matéria orgânica do solo (MOS) e na transferência de nutrientes da biomassa de espécies arbóreas para o solo (Viera \& Schumacher, 2010a). Isso porque a dinâmica de deposição e mineralização da serapilheira florestal é essencial para o retorno de nutrientes ao solo (Ferreira et al., 2007).

A produção e o estoque de serapilheira em ecossistemas terrestres são afetados por diferentes fatores, tais como condições de fertilidade de solo, precipitação pluviométrica, temperatura, luminosidade, condições edafoclimáticas da área, entre outros (Barbosa \& Faria, 2006). Tendo em vista a extensão da degradação do bioma Cerrado, sua biodiversidade e o papel ecológico da serapilheira em ecossistemas terrestres, o presente trabalho teve como objetivo avaliar a camada de serapilheira disposta na superfície do solo (estoque de serapilheira) e suas frações, em duas fitofisionomias, Cerrado Típico e Mata de Galeria, e em um povoamento de Eucalyptus urograndis, durante as duas estações do ano, período de 12 meses.

\section{MATERIAL E MÉTODOS}

A região de estudo localiza-se na Fazenda Água Limpa (FAL) da Universidade de Brasília (UnB), nas coordenadas geográficas $15^{\circ} 31^{\prime} \mathrm{S}$ e $47^{\circ} 42^{\prime} \mathrm{W}$, Lago Sul, Distrito Federal. A FAL possui uma área de aproximadamente 4.340 ha, dos quais 2.340 ha (54\% da área total) são destinados à preservação, 800 ha, à conservação (18\%) e 1.200 ha (28\%), à produção agropecuária e florestal. O clima da região é do tipo Aw, segundo a classificação de Köppen, com duas estações climáticas bem definidas: seca, entre os meses de maio a setembro, e chuvosa, entre outubro e abril. As temperaturas máxima e mínima anual são de $28,5^{\circ} \mathrm{C}$ e $12^{\circ} \mathrm{C}$, respectivamente, e a precipitação média total anual é de $1.600 \mathrm{~mm}$ (Estação Climatológica Automática UnB). De acordo com o Sistema Brasileiro de Classificação de Solos, o solo das áreas avaliadas é classificado como Latossolo Vermelho-Amarelo distrófico típico, de textura argilosa (Embrapa, 2013).

$\mathrm{O}$ estudo foi conduzido em áreas de Cerrado Sentido Restrito (Cerrado Típico), Mata de Galeria e um povoamento clonal GG100 de Eucalyptus urograndis, obtido de híbridos de Eucalyptus urophylla $\times$ Eucalyptus grandis. As mudas foram plantadas no espaçamento de $3 \times 2 \mathrm{~m}$, em dezembro de 2005 . O preparo do solo consistiu de subsolagem a $70 \mathrm{~cm}$ de profundidade, com a incorporação de $500 \mathrm{~kg} \mathrm{ha}^{-1}$ de superfosfato simples e $280 \mathrm{~g} /$ planta de NPK na mistura granulada 20-5-20, mais B e Zn, com a primeira aplicação aos 15 dias após o plantio, e a segunda no início do período chuvoso. A área de estudo passou por um incêndio em setembro de 2011, após quatro anos da implantação das árvores. Apesar disso, a sobrevivência do povoamento não foi afetada.

Em cada área estudada foram obtidas três amostras simples do estoque de serapilheira, coletadas aleatoriamente, a uma distância mínima de $5 \mathrm{~m}$ entre os pontos amostrados. Para tanto, foi empregado como coletor um gabarito metálico quadrado com dimensões 
$0,5 \times 0,5 \mathrm{~m}\left(0,25 \mathrm{~m}^{2}\right)$. As coletas foram realizadas em locais com condições topográficas semelhantes e a uma distância mínima de $20 \mathrm{~m}$ de estradas e aceiros, para evitar possíveis efeitos de borda sobre o estoque de serapilheira. As amostragens foram realizadas mensalmente, entre setembro de 2011 e agosto de 2012.

A serapilheira coletada foi acondicionada em embalagens de papel devidamente identificadas e, posteriormente, foram secas em estufa de circulação forçada de ar, a $65^{\circ} \mathrm{C}$, por um período mínimo de $72 \mathrm{~h}$. Em seguida foram separadas manualmente nas frações folhas, cascas, galhos, raiz, flores/frutos e material particulado (frações $<5 \mathrm{~mm}$ e não identificáveis) e pesadas em balança digital de precisão com de duas casas decimais, para obtenção da massa seca.

A partir da média dos três pontos amostrais em cada área estudada foi determinada a massa seca do estoque de serapilheira total $\left(\mathrm{t} \mathrm{ha}^{-1}\right)$ da amostra composta e as porcentagens de cada fração. Os dados do estoque de serapilheira total foram submetidos à análise de variância (ANOVA), para testar a homocedasticidade e, em seguida, as médias dos dados foram comparadas pelo teste de Tukey ( $\mathrm{p}<0,01)$, a fim de identificar possíveis diferenças entre as fisionomias estudadas. Os dados de massa seca do estoque de serapilheira total e os dados climatológicos (temperatura média, velocidade do vento e precipitação) foram submetidos à análise multivariada de correlações canônicas e avaliadas segundo o teste " $\mathrm{t}$ " de Student para se determinarem as interrelações entre essas variáveis. Todas as análises estatísticas foram realizadas utilizando o Programa Genes (Cruz, 2001).

\section{RESULTADOS E DISCUSSÃO}

Os valores do estoque de serapilheira total anual no período de estudo variaram entre 3,62 tha- $\mathrm{e}^{-1}$ 11,51 tha ${ }^{-1}$ (média de 6,08 $\mathrm{t} \mathrm{ha}^{-1}$ ) para a área de Cerrado Típico; entre 4,49 $\mathrm{t} \mathrm{ha}^{-1} \mathrm{e} 12,56 \mathrm{t} \mathrm{ha}^{-1}$ (média de 9,36 $\mathrm{t} \mathrm{ha}^{-1}$ ) para a Mata de Galeria; e entre 5,92 $\mathrm{t} \mathrm{ha}^{-1}$ e 14,90 $\mathrm{t} \mathrm{ha}^{-1}$ (média de 9,12 $\mathrm{tha}^{-1}$ ) para o povoamento de eucalipto (Figura 1). $\mathrm{O}$ estoque médio total anual na Mata de Galeria foi estatisticamente igual ao observado para o povoamento de eucalipto, cujos valores foram maiores aos verificados no Cerrado Típico. Considerando o somatório dos valores médios do estoque de serapilheira total nas áreas, a Mata de Galeria, o povoamento de eucalipto e o Cerrado Típico apresentaram os seguintes valores de contribuição: $38,11 \%, 37,13 \%$ e $24,76 \%$, respectivamente.

O estoque médio de serapilheira observado na área de Cerrado Típico no presente estudo apresentou valor próximo ao verificado em uma área de Cerrado sensu stricto em Curvelo, MG, (6,46 tha ${ }^{-1}$ ) (Paiva et al., 2011). No entanto, foi menor quando comparado com uma área de Cerrado Típico em Brasília, DF, (média de 7,11 t ha ${ }^{-1}$ )

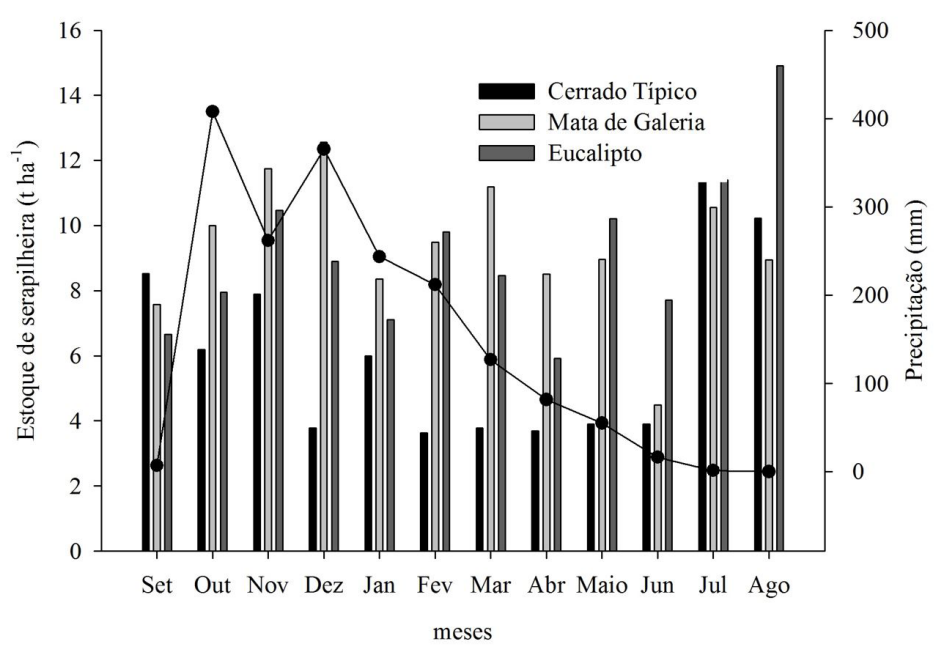

Figura 1. Valores de precipitação pluviométrica e estoque mensal de serapilheira em áreas de Cerrado Típico, Mata de Galeria e povoamento de eucalipto na Fazenda Água Limpa, UnB, Lago Sul, DF.

Figure 1. Values of rainfall and monthly litter stock in Cerrado area, Gallery Forest and eucalyptus plantation in Fazenda Água Limpa/UnB, Lago Sul - DF. 
(Ribeiro et al., 2011). Segundo Ribeiro \& Walter (2008), em Matas de Galeria o estrato arbóreo apresenta altura entre $20 \mathrm{~m} \mathrm{e} 30 \mathrm{~m}$, na qual observa-se uma superposição das copas, que fornecem cobertura arbórea de $70 \%$ a $95 \%$. No seu interior, a umidade relativa é alta, mesmo na época mais seca do ano. Já o Cerrado Típico é uma fitofisionomia predominantemente arbóreo-arbustiva, com altura média de $3 \mathrm{~m}$ a $6 \mathrm{~m}$ e cobertura arbórea de $20 \%$ a 50\%. Dessa maneira, diferenças na composição e tamanho da vegetação podem explicar o maior estoque de serapilheira na Mata de Galeria em relação ao Cerrado Típico.

$\mathrm{O}$ estoque médio de serapilheira verificado no povoamento de eucalipto no presente estudo foi menor do que o observado em outros trabalhos. Em povoamentos de Eucalyptus grandis $\mathrm{x}$ Eucalyptus urophylla com 16 anos e espaçamento $3 \mathrm{~m} \times 3 \mathrm{~m}$ no sul da Bahia, Gama-Rodrigues \& Barros (2002) encontraram 13,5 tha $^{-1}$ de estoque de serapilheira. Balieiro et al. (2004) encontraram o valor de 11,8 $\mathrm{tha}^{-1}$ para o estoque de serapilheira em um povoamento de Eucalyptus grandis com 7 anos de idade e espaçamento $3 \mathrm{~m} \times 1 \mathrm{~m}$, em Seropédica, RJ.

Em povoamentos de Eucalyptus grandis no Norte Fluminense, Cunha et al. (2005) observaram que o estoque de serapilheira foi de $9,6 \mathrm{tha}^{-1}$ (8 anos, primeira rotação, espaçamento $2 \mathrm{~m} \times 2,5 \mathrm{~m}$ ), 13,9 t ha-1 (rebrota com 1,5 ano, segunda rotação, espaçamento 2,5 $\mathrm{m} \times 2,5 \mathrm{~m}$ ) e 23,0 $\mathrm{tha}^{-1}$ (rebrota com 5 anos, espaçamento $2 \mathrm{~m} \times 1,5 \mathrm{~m}$ ). Entretanto, em estudo realizado por Zaia \& Gama-Rodrigues (2004) no Norte Fluminense foram encontrados valores de 4,76 t ha ${ }^{-1}$ ano $^{-1}$, 7,73 t ha $a^{-1}$ noo $^{-1}$ e 9,69 t ha $^{-1}$ ano $^{-1}$ para o estoque de serapilheira em povoamentos de Eucalyptus grandis, Eucalyptus camaldulensis e Eucalyptus pellita, respectivamente, com espaçamento $3 \mathrm{~m} \times 2 \mathrm{~m}$ e 6 anos de idade. Portanto, observa-se que o estoque de serapilheira em florestas plantadas de eucalipto relaciona-se com fatores como idade do povoamento e espaçamento de plantio.

$\mathrm{O}$ estudo da ciclagem de nutrientes envolve avaliações sobre a deposição da serapilheira e a velocidade de sua decomposição (Schumacher et al., 2013). De uma maneira geral, o gênero Eucalyptus sp. apresenta baixas taxas de decomposição da serapilheira, normalmente é necessário mais de um ano para decompor $50 \%$ desse material vegetal, sob diferentes condições edafoclimáticas e de manejo (Gama-Rodrigues \& Barros; Zaia \& Gama-Rodrigues, 2004; Diniz et al., 2011; Viera et al., 2014). Por esse motivo, em povoamentos de eucalipto geralmente os valores de estoque de serapilheira são maiores em comparação com aqueles observados em formações savânicas, como é o caso do Cerrado Típico.

$\mathrm{Na}$ área de Cerrado Típico, os valores das contribuições das frações no estoque de serapilheira em ordem decrescente foram: $4,90 \mathrm{tha}^{-1}(61,67 \%)$ para folhas; 1,83 tha $^{-1}(23,09 \%)$ para o material particulado; $0,99 \mathrm{t} \mathrm{ha}^{-1}(12,49 \%)$ para galhos; $0,17 \mathrm{t} \mathrm{ha}^{-1}(2,20 \%)$ para cascas; $0,04 \mathrm{t} \mathrm{ha}^{-1}(0,50 \%)$ para flores/frutos; e $0,01 \mathrm{t} \mathrm{ha}^{-1}(0,02 \%)$ para raízes (Figura 2$)$.

Para a área de Mata de Galeria, os valores das frações no estoque de serapilheira foram $5,93 \mathrm{tha}^{-1}(51,59 \%)$; 2,62 t ha-1 (22,79\%); 2,13 t ha-1 (18,59\%), 0,34 t ha-1 (3,02\%); $0,25 \mathrm{t} \mathrm{ha}^{-1}(2,19 \%) ; 0,2 \mathrm{t} \mathrm{ha}^{-1}(1,79 \%)$ para folhas, galhos, material particulado, cascas, flores/frutos e raízes, respectivamente (Figura 3 ).

Os dados para as frações no estoque de serapilheira total na área de eucalipto estão apresentados na Figura 4, cujos valores médios de estoque e contribuição percentual foram: $7,32 \mathrm{t} \mathrm{ha}^{-1}(68,01 \%)$ para folhas; $1,65 \mathrm{tha}^{-1}(15,32 \%)$ para material particulado; $1,55 \mathrm{tha}^{-1}$ $(14,37 \%)$ para galhos; $0,21 \mathrm{t} \mathrm{ha}^{-1}(1,90 \%)$ para cascas; $0,02 \mathrm{t} \mathrm{ha}^{-1}(0,18 \%)$ para raízes e $0,02 \mathrm{t} \mathrm{ha}^{-1}(0,18 \%)$ para flores/frutos.

Portanto, entre as frações, as folhas apresentaram os maiores valores de contribuição percentual no estoque de serapilheira total, que variou entre aproximadamente $52 \%$ e $68 \%$, nas áreas estudadas. A predominância da fração foliar no estoque de serapilheira reflete o mesmo padrão observado para a serapilheira produzida em diferentes ecossistemas florestais tropicais, nativos e implantados, segundo os quais a fração foliar representa de $60 \%$ a $80 \%$ do total da serapilheira produzida (Backes et al., 2005; Pires et al., 2006; Ferreira et al., 2007; Pereira et al., 2008; Viera \& Schumacher, 2010b; Schumacher et al., 2013).

Quando comparada às proporções de frações de serapilheira estocada com a serapilheira produzida, as informações obtidas neste trabalho coincidiram com o estudo de Silva et al. (2007). Esses autores observaram que na serapilheira produzida em uma área de Cerrado em Nova Xavantina a fração foliar foi predominante no período seco $(45,16 \%$ do total) e no 
período chuvoso (40,0\%), o que resultou no percentual médio de $42,92 \%$ do total da massa seca. Já o percentual médio de galhos, flores e frutos foi de 18,01\%, 6,75\% e $32,32 \%$, respectivamente (Silva et al., 2007). Em área de cerradão na Estação Ecológica de Pirapitinga, MG, Giácomo et al. (2012) observaram que a sequência decrescente das frações da serapilheira produzida foi: folhas $(71,6 \%)>$ outros $(15,9 \%)>$ galhos $(10,3 \%)>$ sementes $(1,1 \%)>$ frutos $(0,8 \%)>$ flores $(0,3 \%)$.

Em áreas de Mata de Galeria úmida (margem de córrego), intermediária e seca (ambas referentes às comunidades vegetais na borda da mata) na Reserva Ecológica do IBGE - DF, 70\% da serapilheira total produzida foi representada pela fração foliar

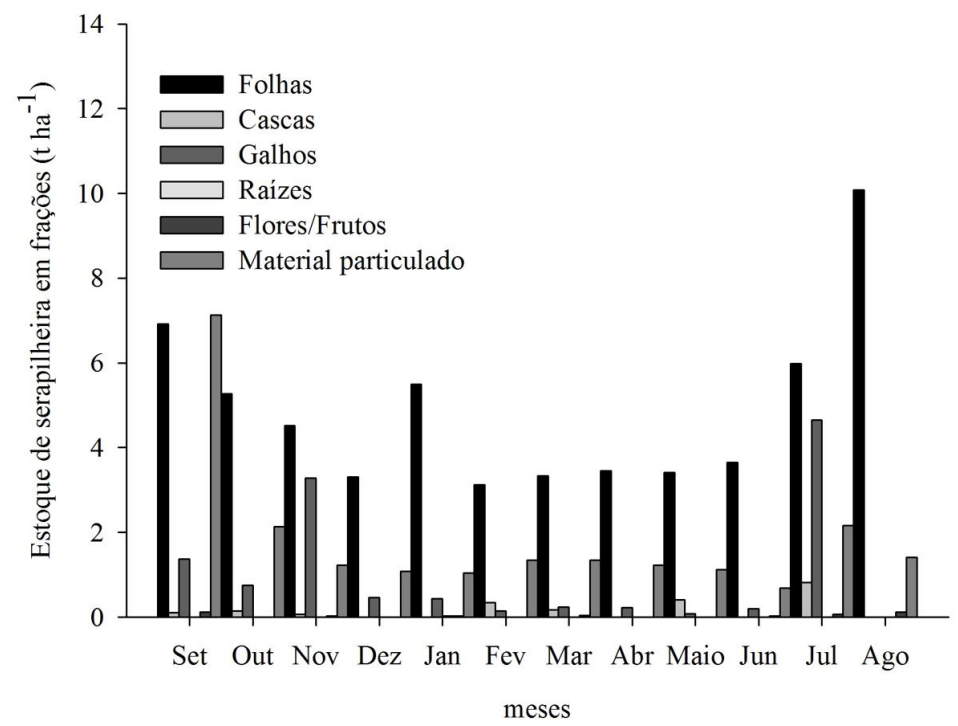

Figura 2. Estoque mensal das frações de serapilheira em área de Cerrado Típico na Fazenda Água Limpa, UnB, Lago Sul, DF.

Figure 2. Monthly litter fractions stock in a Typical Cerrado area in Fazenda Água Limpa/UnB, Lago Sul - DF.

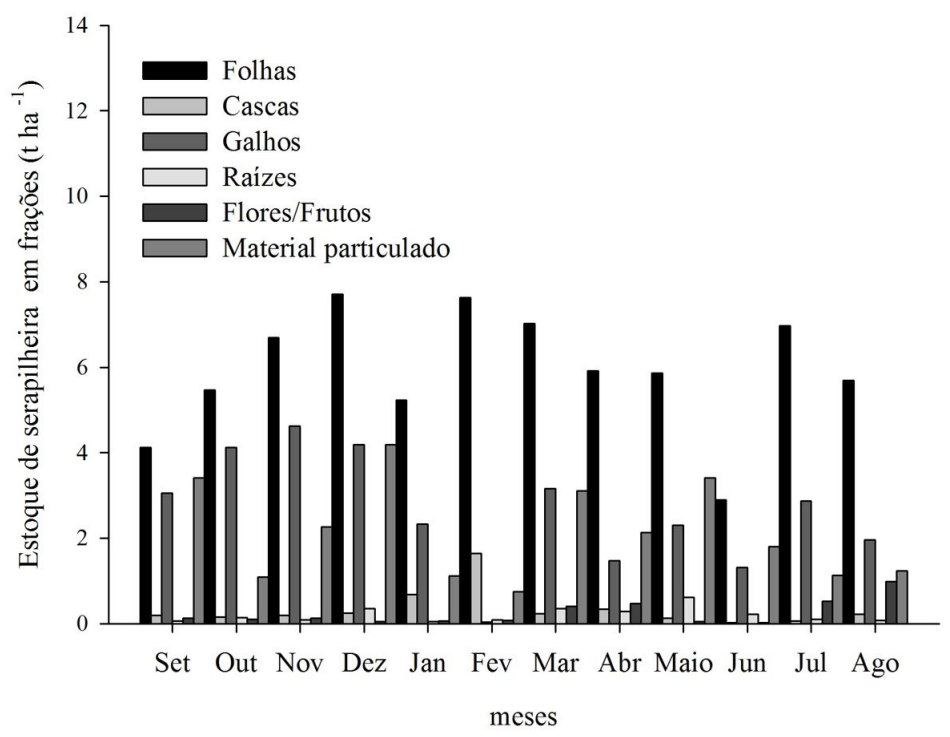

Figura 3. Estoque mensal das frações de serapilheira em área de Mata de Galeria na Fazenda Água Limpa, UnB, Lago Sul, DF.

Figure 3. Monthly litter fractions stock in a Gallery Forest area in Fazenda Água Limpa/UnB, Lago Sul - DF. 


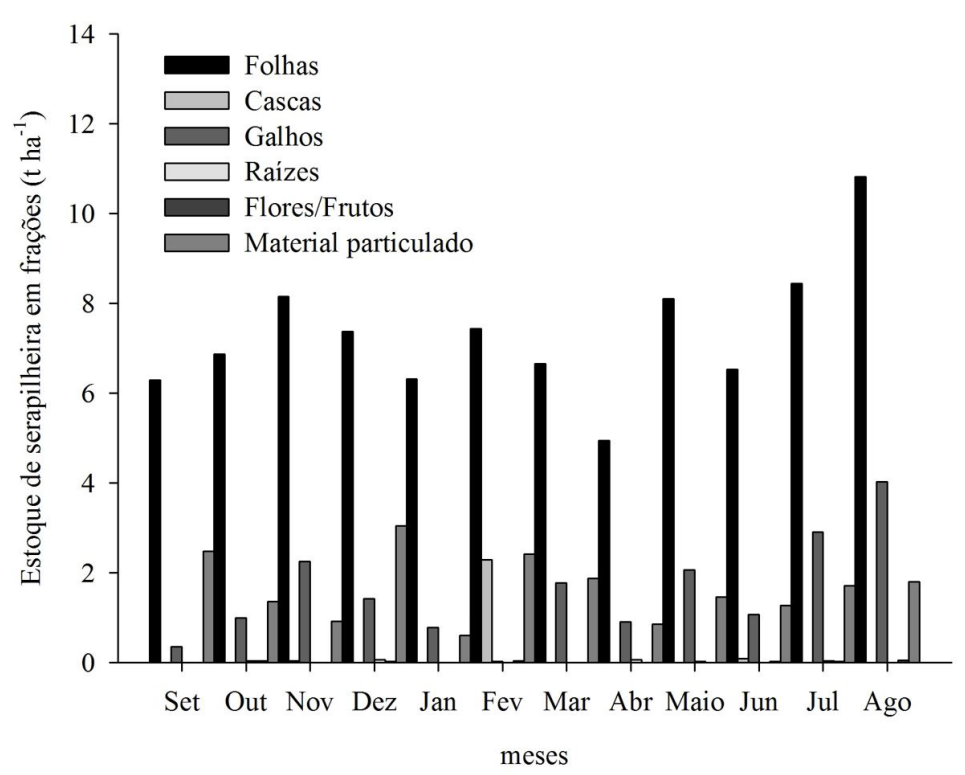

Figura 4. Estoque mensal das frações de serapilheira em um povoamento de Eucalyptus urograndis na Fazenda Água Limpa, UnB, Lago Sul, DF.

Figure 4. Monthly litter fractions stock in a Eucalyptus urograndis plantation in Fazenda Água Limpa/UnB, Lago Sul - DF

(Parron \& Bustamante, 2004). O estudo conduzido por Lagos (2009) em uma região de Cerrado em Nova Xavantina, MT, em três porções da Mata de Galeria do Córrego Bacaba, mostrou que os valores percentuais obtidos para a fração foliar foram de $60 \%$ com relação à serapilheira total produzida.

Quanto ao povoamento de eucalipto, o percentual de folhas encontrado no estoque de serapilheira se aproximou de 70\%. Viera et al. (2014), ao estudarem a disponibilidade de nutrientes no município de Eldorado do Sul, RS, em uma plantação de Eucalyptus urophylla x Eucalyptus globulus com 5,5 anos de idade, observaram que a fração de folhas correspondeu a $66,9 \%$ do estoque total de serapilheira. Na mesma região, Schumacher et al. (2013) observaram que a fração folhas contribuiu com $70 \%$ do estoque total de serapilheira em um povoamento de Eucalyptus urophylla $\mathrm{x}$ Eucalyptus globulus com 5,6 anos de idade.

Em relação à sazonalidade, tanto no Cerrado Típico quanto no povoamento de eucalipto, os maiores valores da fração foliar no estoque de serapilheira foram observados no período de menor precipitação pluviométrica (Figuras 1, 2 e 4). Padrão oposto ocorreu na Mata de Galeria, onde a fração foliar apresentou maior contribuição para o estoque de serapilheira durante o período de maior precipitação (Figuras 1 e 3).
Os dois padrões contrastantes de sazonalidade verificados foram corroborados pelos pares canônicos, que apresentaram-se significativos (> 1\%). Vento, precipitação, temperatura (Grupo I) e estoque de serapilheira (Grupo II) das três áreas não foram considerados independentes e as associações intergrupos foram estabelecidas, principalmente, pela influência da velocidade do vento. Esse fator tem grande efeito sobre a produção de serapilheira e, consequentemente, refletiu em maior estoque de serapilheira nas áreas de eucalipto e Cerrado Típico. Já a precipitação e temperatura (ambos do Grupo I) contribuíram para o aumento do estoque de serapilheira na Mata de Galeria (Tabela 1).

Campos et al. (2008) e Cianciaruso et al. (2006) também observaram correlação significativa e inversamente proporcional entre a produção da fração folhas e a precipitação, em fragmentos de mata mesofítica e Cerrado strictu senso em Uberlândia, $\mathrm{MG}$, e em região de cerradão na Estação Ecológica de Jataí - MG. Por outro lado, Santos-Neto et al. (2015) verificaram que houve correlação significativa diretamente proporcional entre precipitação e quantidade de folhas depositadas em povoamentos de amendoim bravo (Pterogyne nitens Tul.) e de Eucalyptus urophylla no sudoeste da Bahia. 
Tabela 1. Correlações canônicas estimadas entre dados climatológicos (Grupo I) e o estoque de serapilheira total (Grupo II) em áreas de Cerrado Típico, Mata de Galeria e povoamento de eucalipto na Fazenda Água Limpa, UnB, Lago Sul, DF.

Table 1. Canonical correlations estimated between climatological data (Group I) and total litter stock (Group II) in Cerrado area, Gallery Forest and eucalyptus plantation in Fazenda Água Limpa/UnB, Lago Sul - DF.

\begin{tabular}{lcc}
\multirow{2}{*}{\multicolumn{1}{c}{ Variáveis }} & \multicolumn{2}{c}{ Pares canônicos } \\
\cline { 2 - 3 } & $\mathbf{1}^{\mathbf{o}}$ & $\mathbf{2}^{\mathbf{0}}$ \\
\hline Precipitação & $-0,42687$ & 0,79054 \\
Vento & 0,85185 & 0,52208 \\
\hline Temperatura & $-0,09788$ & 0,87095 \\
& & \\
\hline Serapilheira de Eucalipto & 0,80031 & $-0,27491$ \\
\hline Serapilheira de Cerrado Típico & 0,96694 & 0,0514 \\
\hline Serapilheira de Mata de Galeria & $-0,22882$ & 0,83279 \\
\hline Significância & $<0,01$ & $<0,01$ \\
\hline
\end{tabular}

Vários estudos sugeriram que o padrão de maior queda da serapilheira na estação seca, o qual reflete-se no aumento do estoque de serapilheira nesse período, é um mecanismo pelo qual a vegetação arbórea minimiza perdas de água via evapotranspiração durante a época de estiagem, na qual ocorre déficit hídrico (Moreira \& Silva, 2004; Andrade et al., 2008; Lima et al., 2015; Silva et al., 2007; Vital et al., 2004). Já o maior estoque de serapilheira na estação chuvosa foi verificado para a Mata de Galeria, o que provavelmente ocorreu em função da maior queda de folhas e, em alguns casos, de galhos, o que geralmente ocorre em florestas sem restrição hídrica severa durante a estação chuvosa. Nesse caso, o efeito mecânico da precipitação e de ventos com maior intensidade nesse período seria o motivo da maior deposição de serapilheira no período de maior precipitação, conforme sugerem Campos et al. (2008). Durante o período do ano que apresenta maiores temperaturas e precipitação, a maior queda de folhas também pode ser um reflexo do aumento da ciclagem interna de nutrientes na planta, pois com a senescência desse material os nutrientes nele encontrados são translocados para diferentes órgãos em crescimento, como sugerido para plantações de Eucalyptus urophylla $\mathrm{x}$ Eucalyptus globulus, no sul do Brasil (Viera et al., 2014).

\section{CONCLUSÕES}

O estoque médio total anual na Mata de Galeria foi estatisticamente igual ao observado no povoamento de eucalipto, cujos valores foram maiores aos verificados no Cerrado Típico.

O maior estoque mensal de serapilheira total na Mata de Galeria ocorreu no período chuvoso, enquanto que os maiores estoques mensais para o Cerrado Típico e para o povoamento de eucalipto ocorreram no período seco.

A fração folhas apresentou a maior contribuição com relação ao estoque total da serapilheira, nas três áreas estudadas.

\section{AGRADECIMENTOS}

Os autores agradecem ao CNPq, pelo auxílio financeiro, a administração da Fazenda Água Limpa, o Departamento de Engenharia Florestal, Faculdade de Tecnologia - Universidade de Brasília.

\section{STATUS DA SUBMISSÃO}

Recebido: 14 dez., 2014

Aceito: 12 jul., 2016

\section{AUTOR(ES) PARA CORRESPONDÊNCIA}

\section{Fabiana Piontekowski Ribeiro}

Pós-graduação em Ciências Florestais, Departamento de Engenharia Florestal, Universidade de Brasília - UnB, Campus Universitário Darcy Ribeiro, CEP 70910-900, Brasília, DF, Brasil e-mail:fbn2.ribeiro@gmail.com

\section{REFERENNCIAS}

Andrade RL, Souto JS, Souto PC, Bezerra DM. Deposição de serrapilheira em área de Caatinga na RPPN "Fazenda Tamanduá, Santa Terezinha - PB. Caatinga 2008; 21: 223-230.

Backes A, Prates FL, Viola MG. Produção de serapilheira em Floresta Ombrófila Mista, em São Francisco de Paula, Rio Grande do Sul, Brasil. Acta Botanica Brasílica 2005; 19(1): 155-160. http://dx.doi.org/10.1590/S010233062005000100015 . 
Balieiro FC, Franco AA, Pereira MG, Campello EFC, Dias LE, Faria SM et al. Dinâmica da serapilheira e transferência de nitrogênio ao solo, em plantios de Pseudosamanea guachapele e Eucalyptus grandis. Pesquisa Agropecuária Brasileira 2004; 39(6): 597-601. http://dx.doi.org/10.1590/ S0100-204X2004000600012.

Barbosa JHC, Faria SM. Aporte de serrapilheira ao solo em estágios sucessionais florestais na reserva biológica de poço das antas, Rio de Janeiro, Brasil. Rodriguésia 2006; 57: 461-476.

Campos EH, Alves RR, Serato DS, Rodrigues GSSC, Rodrigues SC. Acúmulo de serrapilheira em fragmentos de mata mesofítica e Cerrado stricto senso em Uberlândia - MG. Sociedade \& Natureza 2008; 20(1): 189-203. http:// dx.doi.org/10.1590/S1982-45132008000100013.

Cianciaruso MV, Pires JSR, Delitti WBC, Silva EFLP. Produção de serapilheira e decomposição do material foliar em um cerradão na Estação Ecológica de Jataí, município de Luiz Antônio, SP, Brasil. Acta Botanica Brasílica 2006; 20(1): 49-59. http://dx.doi.org/10.1590/ S0102-33062006000100006.

Companhia Nacional de Abastecimento - CONAB. Acompanhamento da safra brasileira: grãos: décimo levantamento: julho/2013 [online]. Brasília; 2013 [citado em 2015 out 1]. Disponível em: http://www.conab.gov. br/conteudos.php?a=1028

Cruz CD. Programa Genes: aplicativo computacional em genética e estatística. Viçosa: UFV; 2001. 648 p.

Cunha GM, Gama-Rodrigues AC, Costa GS. Ciclagem de nutrientes em Eucalyptus grandis W. Hill ex Maiden no Norte Fluminense. Revista Árvore 2005; 29(3): 353-363. http://dx.doi.org/10.1590/S0100-67622005000300002.

Diniz AR, Pereira MG, Loss A. Aporte de material decíduo e nutrientes para o solo em plantio de eucalipto e floresta secundária. Pesquisa Florestal Brasileira 2011; 31(65): 1926. http://dx.doi.org/10.4336/2011.pfb.31.65.19.

Empresa Brasileira de Pesquisa Agropecuária - EMBRAPA. Sistema brasileiro de classificação de solos. 3. ed. Brasília: EMBRAPA; 2013. 353 p.

Ferreira RLC, Lira MA Jr, Rocha MS, Santos MVF, Lira MA, Barreto LP. Deposição e acúmulo de matéria seca e nutrientes em serapilheira em um bosque de sabiá (Mimosa caesalpiniifolia Benth.). Revista Árvore 2007; 31(1): 7-12. http://dx.doi.org/10.1590/S0100-67622007000100002.

Gama-Rodrigues AC, Barros NF. Ciclagem de nutrientes em floresta natural e em plantios de eucalipto e de dandá no sudeste da Bahia, Brasil. Revista Árvore 2002; 26: 193-207.

Giácomo RG, Pereira MG, Machado DL. Aporte e decomposição de serapilheira em áreas de cerradão e mata mesofítica na estação ecológica de Pirapitinga - MG. Revista Ciência Florestal 2012; 22: 669-680.

Lagos MCC. Produção de serapilheira e chuva de sementes em uma floresta de galeria em Nova Xavantina - MT [dissertação]. Nova Xavantina: Departamento de Ciências Florestais, Universidade do Estado de Mato Grosso; 2009.

Lima RP, Fernandes MM, Fernandes MRM, Matricardi EAT. Aporte e decomposição da serapilheira na Caatinga no Sul do Piauí. Floresta e Ambiente 2015; 22(1): 42-49. http://dx.doi.org/10.1590/2179-8087.062013

Moreira PR, Silva OA. Produção de serapilheira em área reflorestada. Revista Árvore 2004; 28(1): 49-59. http:// dx.doi.org/10.1590/S0100-67622004000100007.

Paiva AO, Rezende AV, Pereira RS. Estoque de carbono em Cerrado sensu stricto do Distrito Federal. Revista Árvore 2011; 35(3): 527-538. http://dx.doi.org/10.1590/ S0100-67622011000300015.

Parron LM, Bustamante MMC. Produção e composição química de serapilheira em um gradiente topográfico em Mata de Galeria no Bioma Cerrado do Distrito Federal. Planaltina: Embrapa Cerrados; 2004. 23 p. Boletim de Pesquisa e Desenvolvimento n. 128.

Pereira MG, Menezes LFT, Schultz N. Aporte e decomposição da serapilheira na Floresta Atlântica, Ilha da Marambaia, Mangaratiba, RJ. Ciência Florestal 2008; 18(4): 443-454. http://dx.doi.org/10.5902/19805098428.

Pires LA, Britez RM, Martel G, Pagano SN. Produção, acúmulo e decomposição da serapilheira em uma restinga da Ilha do Mel, Paranaguá, PR, Brasil. Acta Botanica Brasílica 2006; 20(1): 173-184. http://dx.doi.org/10.1590/ S0102-33062006000100016.

Ribeiro JF, Walter BMT. As principais fitofisionomias do Bioma Cerrado. In: Sano MS, Almeida SP. Cerrado: ecologia e flora. Brasília: Embrapa; 2008. p. 153-212.

Ribeiro SC, Fehrmann L, Soares CPB, Jacovine LAG, Kleinn C, Gaspar RO. Above and belowground biomass in a Brazilian Cerrado. Forest Ecology and Management 2011; 262(3): 491-499. http://dx.doi.org/10.1016/j. foreco.2011.04.017.

Sano EE, Rosa R, Brito JL, Ferreira LG. Mapeamento semidetalhado do uso da terra do bioma Cerrado. Pesquisa Agropecuária Brasileira 2008; 43(1): 153-156. http://dx.doi. org/10.1590/S0100-204X2008000100020.

Santos-Neto AP, Barreto PAB, Gama-Rodrigues EF, Novaes AB, Paula A. Produção de serapilheira em floresta estacional semidecidual e em plantios de Pterogyne nitens tul. e Eucalyptus urophylla S. T. Blake no sudoeste da Bahia. Ciência Florestal 2015; 25(3): 633-643. http:// dx.doi.org/10.5902/1980509819614.

Schumacher MV, Corrêa RS, Viera M, Araújo EF. Produção e decomposição de serapilheira em um povoamento de Eucalyptus urophylla $x$ Eucalyptus globulus maidenii. Revista Cerne 2013; 19(3): 501-508. http://dx.doi.org/10.1590/ S0104-77602013000300018. 
Silva CJ, Sanches L, Bleich ME, Lobo FA, Nogueira JS. Produção de serrapilheira no Cerrado e Floresta de Transição Amazônia-Cerrado do Centro-Oeste Brasileiro. Acta Amazonica 2007; 37(4): 543-548. http://dx.doi. org/10.1590/S0044-59672007000400009.

Viera M, Schumacher MV, Araujo EF, Corrêa RS, Caldeira MVW. Deposição de serapilheira e nutrientes em plantio de Eucalyptus urophylla $\times$ E. globulus. Revista Floresta e Ambiente 2014; 21(3): 327-338. http://dx.doi. org/10.1590/2179-8087.053913.

Viera M, Schumacher MV. Variação mensal da deposição de serapilheira em povoamento de Pinus taeda em área de campo nativo em Cambará do Sul - RS. Revista Árvore 2010a; 34(3): 487-494. http://dx.doi.org/10.1590/S010067622010000300012 .
Viera M, Schumacher MV. Deposição de serapilheira e de macronutrientes em um povoamento de acácianegra (Acacia mearnsii De Wild.) no Rio Grande do Sul. Ciência Florestal 2010b; 20(2): 225-233. http://dx.doi. org/10.5902/198050981848.

Vital ART, Guerrini IA, Franken WK, Fonseca RCB. Produção de serapilheira e ciclagem de nutrientes de uma floresta estacional semidecidual em zona ripária. Revista Árvore 2004; 28(6): 793-800. http://dx.doi.org/10.1590/ S0100-67622004000600004.

Zaia FC, Gama-Rodrigues AC. Ciclagem e balanço de nutrientes em povoamentos de eucalipto na região norte Fluminense. Revista Brasileira de Ciência do Solo 2004; 28(5): 843-852. http://dx.doi.org/10.1590/S010006832004000500007 . 